\title{
Climate loads in insulating glass units: comparison of theory and experimental results
}

\author{
Stephan Buddenberg • Peter Hof • \\ Matthias Oechsner
}

Received: 15 February 2016 / Accepted: 26 April 2016 / Published online: 11 May 2016

(C) Springer International Publishing Switzerland 2016

\begin{abstract}
The verification of insulating glass units in ultimate limit state often gives rise to the question of how to take into account the edge seal in the design of the glass panes. Usually the edge seal is calculated as immovable, as this is a more conservative assumption. A flexible edge seal, as to be expected under realistic conditions, leads to a lower climate load and therefore to lower stresses in the glass. In order to determine the influence of a flexible support on the verification of the ultimate limit state under the applicable standards in Germany, various setups of insulating glass units were subjected to cyclically recurring temperatures of -18 to $+53{ }^{\circ} \mathrm{C}$ in a climate chamber. In this procedure, the atmospheric pressure was measured as well as the pressure in the cavity, as were the deformations of the edge seal orthogonally to the glass panes. Based on these, a comparison of analytical calculations of the climate load and the experimentally determined climate load is conducted. By means of the experimentally determined pressure difference in the cavity and the measured deformations of the edge seal, an effective spring stiffness in tension of the edge seal under the climatic test conditions was calculated using a finite element (FE) model. On the basis of an effective spring stiffness in tension assumed in a FE simulation, the influence of a flexible edge seal on the design of the glass panes is determined and discussed.
\end{abstract}

S. Buddenberg ( $\varangle)$. P. Hof · M. Oechsner

Materialprüfungsanstalt Darmstadt, Darmstadt, Germany

e-mail: buddenberg@mpa-ifw.tu-darmstadt.de
Keywords Insulating glass unit . Climate load . Flexible edge seal $\cdot$ Spring stiffness

\section{Introduction}

An insulating glass unit (IGU) consists of two or more glass panes bonded to one another by means of a spacer, so that an insulated cavity results. The cavity is often filled with argon, krypton or xenon to reduce heat conductivity. Spacer and glass panes are bonded to one another using a primary seal made of the thermoplastic material polyisobutylene as well as a secondary seal made of an elastomeric material (polysulphide, polyurethane or silicone) (cf. Fig. 1a).

The cavity is hermetically sealed from the atmosphere via this bond. In case of changes in the atmospheric pressure or pressure in the cavity, a pressure difference between cavity and ambient air arises which acts as a load on the glass panes and edge seal. These pressure differences are also expressed as climate load. They are generated by

(a) the altitude of installation with respect to production, as this will change the atmospheric pressure,

(b) meteorological air pressure changes,

(c) temperature changes of the gas in the cavity (cf. Fig. 1b).

The larger the cavity or the shorter the edge lengths, the greater the climate load will be. Thicker glass panes 
(a)

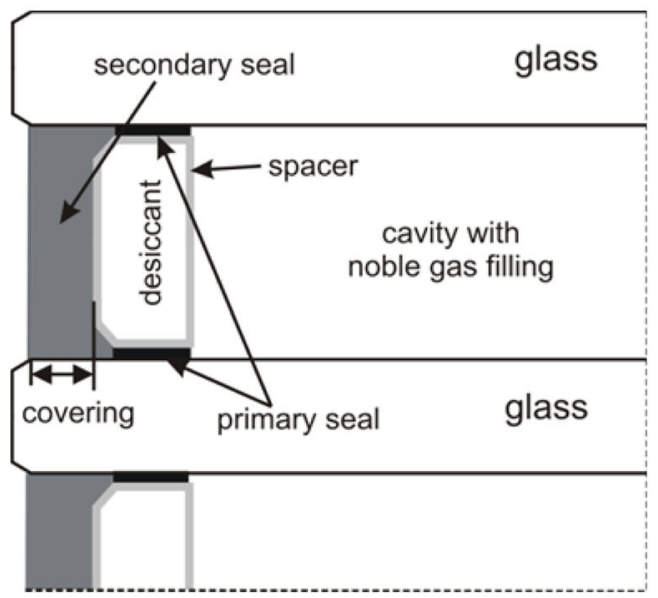

(b)

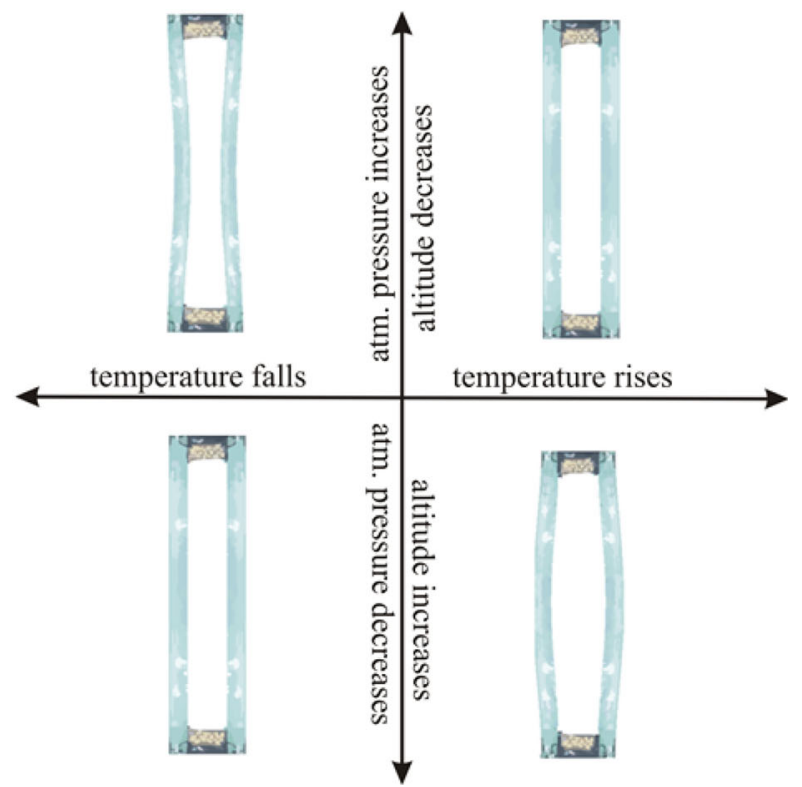

Fig. 1 a Cross-section of a typical conventional edge seal from an IGU; b influence of climatic changes on an IGU

also increase the climate load, as these bend less, allowing only a smaller change in the volume of gas in the cavity. In small insulating glass units, the climate load with respect to other loads such as wind, becomes dominant for the design of glass panes in ultimate limit state (ULS).

In the currently used concept for design of glass panes of insulating glass units, the structural support of the glass panes on the edges is assumed to be immovable. This provides a margin of safety in terms of verification in ULS. In practice the edge seal is flexible, however, resulting in a lower climate load, because larger volume changes of the gas in the cavity are possible. In the design therefore, a spring support on the edges could be assumed. This will have an economically favourable effect on small insulating glass units because of a lower climate load. The objective of this article is to discuss the approach of using a flexible edge seal in the design of glass panes of insulating glass units. For this purpose, experimentally determined climate loads and the point deformation of the edge seal of specimens are introduced, which were subjected to cyclic loading at temperatures of -18 to $+53{ }^{\circ} \mathrm{C}$ in a climate chamber for 4 weeks. From these, effective spring stiffness in tension for the edge seal were determined using finite elements (FE) calculations. With these known effective spring stiffnesses in tension and the resultant lower climate loads, the lower glass stresses thus effected are calculated and compared with the glass stresses arising from the conventional approach of an immovable edge seal. In view of the current standards in Germany, discussions are taking place regarding the conditions under which this approach would be meaningful. The structure of this article includes first of all a general assessment in Sect. 2 on how climate loads are determined and how a design of insulating glass units under climate load is conducted in accordance with the current German standards (DIN 18008-1 2010; DIN 18008-2 2010). For this purpose, results of exemplary calculations for design are provided in addition. In Sect. 3, subsequently climate loads and the associated deformations of the edge seal which have been experimentally determined and analytically calculated in a climate test are illustrated and discussed. The effective spring stiffnesses in tension based on this are considered in a FE model in order to examine the influence of the flexibility of the edge seal on the design.

\section{State of the art}

\subsection{Determination of climate loads}

To determine climate loads, the pressure inside the cavity, calculated e.g. via the assumption of an ideal gas, and the resulting deformation of the glass panes based 
Conditions of production (pr)

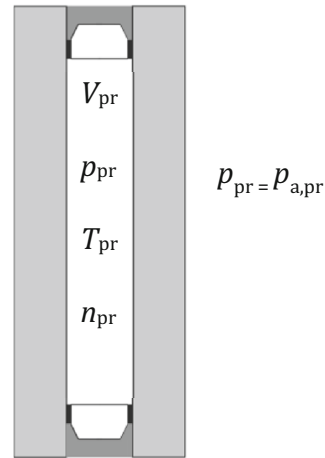

Current conditions (1)

Fig. 2 Deformations due to changes of temperature, atmospheric pressure and amount of substance compared to the conditions of production

on load must be taken into account. The deformation of the edge seal can be disregarded for the moment, as this is also not assumed in the usual analytical calculation methods. For an analytical determination in this instance, the solution of the linear plate theory according to Kirchhoff for rectangular, planar plates with immovable support is commonly used. On this basis, Feldmeier (1999) developed an approach for the design of the arising volume under a plate due to area load:

$$
\begin{aligned}
& \Delta V=\frac{A_{\mathrm{v}}(e) \cdot a^{6}}{e \cdot K} \cdot \Delta p=\Omega \cdot \Delta p \\
& \text { with } e=\frac{a}{b} ; K=\frac{E d^{3}}{12\left(1-v^{2}\right)} ; \\
& A_{\mathrm{V}}(e)=\frac{1}{120}-\frac{24 e}{\pi^{7}} \sum_{n=1,3, \ldots} \frac{1}{n^{7}}\left\{\tanh \gamma_{n}\right. \\
& \left.-\frac{\gamma_{n}}{3 \cosh ^{2} \gamma_{n}}\right\} ; \gamma_{n}=\frac{n \pi}{2 e}
\end{aligned}
$$

and $a$, length of the short edge $(\mathrm{m}) ; b$, length of the long edge $(\mathrm{m}) ; \Delta p$, pressure difference between cavity and atmosphere (climate load) $\left(\mathrm{N} / \mathrm{m}^{2}\right) ; E$, Young's modulus $\left(\mathrm{N} / \mathrm{m}^{2}\right) ; d$, thickness of the (glass) plates $(\mathrm{m})$; $v$ Poisson's ratio; $\Omega$, coefficient of the volume below the plate under area load $\left(\mathrm{m}^{5} / \mathrm{N}\right)$.

Under the assumption of a symmetric setup of the insulating glass units, it follows that the entire additional volume corresponds to $2 \cdot \Delta V$ (cf. Fig. 2).

From the ideal gas law

$$
p \cdot V=n \cdot R \cdot T \rightarrow \frac{p \cdot V}{n \cdot T}=\text { const. }
$$

with $p$, gas pressure $\left(\mathrm{N} / \mathrm{m}^{2}\right) ; p_{a}$, atmospheric air pressure $\left(\mathrm{N} / \mathrm{m}^{2}\right) ; V$, gas volume $\left(\mathrm{m}^{3}\right) ; R$, general gas constant $[\mathrm{J} /(\mathrm{mol} \cdot \mathrm{K})] ; T$, gas temperature $(\mathrm{K}) ; n$, amount of substance (mol) follows that

$\frac{p_{\mathrm{pr}} \cdot V_{\mathrm{pr}}}{n_{\mathrm{pr}} \cdot T_{\mathrm{pr}}}=\frac{p_{1} \cdot V_{1}}{n_{1} \cdot T_{1}}$

with $V_{1}=V_{\mathrm{pr}}+2 \cdot \Delta V$ and $p_{1}=p_{\mathrm{a}, 1}+\Delta p$

With the application of Eq. (1) in (3) follows the solution to the calculation of the pressure difference for rectangular, planar and symmetric IGU under consideration of a loss of amount of substance $n_{1} / n_{\mathrm{pr}}$ :

$$
\begin{aligned}
& \Delta p_{1,2}=-\frac{\left(\frac{V_{\mathrm{pr}}}{2 \Omega}+p_{\mathrm{a}, 1}\right)}{2} \\
& \pm \sqrt{\frac{\left(\frac{V_{\mathrm{pr}}}{2 \Omega}+p_{\mathrm{a}, 1}\right)^{2}}{4}+\left(\frac{p_{\mathrm{pr}} \cdot V_{\mathrm{pr}} \cdot T_{1}}{T_{\mathrm{pr}}} \cdot \frac{n_{1}}{n_{\mathrm{pr}}}-p_{\mathrm{a}, 1} \cdot V_{\mathrm{pr}}\right) \cdot \frac{1}{2 \Omega}}
\end{aligned}
$$

For symmetric triple IGU it is assumed, that the pressure within both cavities is approximately equal. This assumption presumes that glass thicknesses and cavity widths do not differ significantly.

In the linear plate theory according to Kirchhoff it is simplistically assumed that the plates deform in a geometrically linear fashion. In practice, membrane action interferes with the bending, causing plates to behave in a more rigid fashion than in linear plate theory determined using Kirchhoff's method. As a result, climate loads are higher than calculated by this approach. This must be taken into account in the assessment of the comparison of the experimentally determined and analytically calculated climate load, which is conducted in Sect. 3 as follows further below. In addition to the disregard of geometric nonlinearity, the deformation of the plates due to shear forces is not applied in the Kirchhoff plate theory. Both effects can be estimated relatively easily using the finite element method and the proper choice of element.

In order to estimate the influence of the named effects and assess the comparison of experimentally determined loads with analytically calculated loads in Sect. 3, Table 1 illustrates the differences of analytically determined climate load and stresses based on plate theory according to Kirchhoff using the calculation method of DIN 18008-2 (2010) and FE calculations. The climate loads were calculated with data on the load condition "winter" from DIN 18008-1 (2010) 
Table 1 Comparison of climate loads and stresses based on Kirchhoff's plate theory with results of an FE model in consideration of the influence of geometrical nonlinearity and shear- flexible plate for symmetric IGU for the load condition "winter" in accordance with DIN 18008-1 (2010)

\begin{tabular}{lclll}
\hline Dimensions $\left(\mathrm{mm}^{2}\right)$ & Glass thickness $(\mathrm{mm})$ & Cavity $(\mathrm{mm})$ & $\Delta p_{\mathrm{K}} / \Delta p_{\mathrm{FE}}(\%)$ & $\sigma_{\max , \mathrm{K} / \sigma_{\max , \mathrm{FE}}(\%)}$ \\
\hline $350 \times 500$ & 3 & $1 \times 12$ & 97.0 & 99.0 \\
$350 \times 500$ & 4 & $2 \times 12$ & 98.6 & 99.9 \\
$350 \times 500$ & 12 & $2 \times 12$ & 100 & 98.2
\end{tabular}

with $\sigma_{\max }=$ maximal first principal stress $(\mathrm{MPa})$ and the indices $\mathrm{K}=$ Kirchhoff and $\mathrm{FE}=$ finite element

for temperature and for atmospheric pressure. The FE model was generated in ANSYS 16.0 with a Shell181 element for the modelling of the glass plate, and an HSFLD241 element for the modelling of the gas volume via utilization of the symmetries, where the glass plate is not movably supported on the edges. A geometrically nonlinear calculation was done. Results for dimensions and setups of insulating glass units, which were also available as specimens in the tests described in this article, are illustrated.

As apparent in Table 1, the analytically and numerically calculated stresses in glass panes of 3 and $4 \mathrm{~mm}$ thicknesses hardly vary. Only in the very thick $12 \mathrm{~mm}$ glass panes is a somewhat higher difference of $1.8 \%$ recognizable. For the design, these small differences play a subordinate role, which is the reason that disregarding them in practice is justified. The climate load, however, is already underestimated with $3 \%$ at a glass thickness of $3 \mathrm{~mm}$.

\subsection{Design of insulating glass units under climate load and exemplary calculations}

In the design of insulating glass units in ULS, as usual in civil engineering today at the European level with the introduction of the German standard DIN 18008 (2010), the partial factor method with $E_{\mathrm{d}} \leq R_{\mathrm{d}}$ is also applied to glass structures. The failure probability target in civil engineering is $1 \times 10^{-6}$ in 1 year, which is secured with safety factors on the impact and resistance side. In climate load, the normative design action $E_{\mathrm{d}}$ contains height differences as permanent actions with the partial safety factor $\gamma_{\mathrm{G}}=1.35$ and impacts from temperature and meteorological fluctuations consolidated as variable actions with the factor $\gamma_{\mathrm{Q}}=1.5$ (DIN 18008-1 2010; EN 1990 2010). In accordance with German standardisation, only a design of the glass is carried out, not including the edge seal, unless it were assumed to be load-bearing. The design of the edge seal is not subject of the article. The design value of the design resistance $R_{\mathrm{d}}$ for glass is determined in accordance with DIN 18008-1 (2010) using the following formula:

$R_{\mathrm{d}}=\frac{k_{\mathrm{mod}} \cdot k_{\mathrm{c}} \cdot f_{\mathrm{k}}}{\gamma_{\mathrm{m}}}$

with $k_{\text {mod }}$, modification factor of impact duration in float glass, omitted in heat-strengthened and toughened glass; $k_{c}$, type of construction; $f_{\mathrm{k}}$, characteristic value of flexural strength (MPa); $\gamma_{\mathrm{M}}$, material safety factor.

For the typical glass products used in insulating glass units, i.e. float glass, heat-strengthened glass and toughened glass, the following results pertain when line support of all four edges of the construction under climate load is present: a bearing capacity of $R_{\mathrm{d}}=18 \mathrm{MPa}$ for float glass, $R_{\mathrm{d}}=46.7 \mathrm{MPa}$ for heat strengthened glass and $R_{\mathrm{d}}=80 \mathrm{MPa}$ for toughened glass (DIN 18008-1 2010; DIN 18008-2 2010; EN 572-1 2012; EN 1863-1 2012; EN 12150-1 2015), whereas the costs of strengthened glass versus toughened glass hardly vary. The differences in bearing capacity result on the one hand from the respective characteristic strengths of the products as well as from the consideration of the timedependent resistance of glass. Other impacting factors resulting from wind, snow and self-weight are not discussed in this article, as these usually only become decisive in the larger pane dimensions. Within DIN 18008-2 (2010), an exemption provision for verification in ULS for IGU is defined. This applies to dimensions with a glass surface area smaller than $1.6 \mathrm{~m}^{2}$ and IGU in vertical application under wind load, self-weight and climate load. If the following limitations apply to an IGU in addition, the bearing capacity does not have to be confirmed. Float glass with a thickness of at least $4 \mathrm{~mm}$ may be used. 
Table 2 Combination of actions in accordance with DIN 18008-1 (2010)
Table 3 Consideration of special temperature conditions at the installation site in accordance with DIN 18008-1 (2010)

\begin{tabular}{llll}
\hline $\begin{array}{l}\text { Combination } \\
\text { of actions }\end{array}$ & $\begin{array}{l}\text { Temperature } \\
\text { difference }(\mathrm{K})\end{array}$ & $\begin{array}{l}\text { Change in atmospheric } \\
\text { pressure, } \Delta p_{\text {met }}\left(\mathrm{kN} / \mathrm{m}^{2}\right)\end{array}$ & $\begin{array}{l}\text { Location height } \\
\text { difference (m) }\end{array}$ \\
\hline "Summer" & +20 & -2.0 & +600 \\
"Winter" & -25 & +4.0 & -300 \\
\hline
\end{tabular}

\begin{tabular}{llc}
\hline Combination of actions & Cause of increased temperature difference & $\Delta T_{\text {add }}(\mathrm{K})$ \\
\hline "Summer" & Absorption between 30 and $50 \%$ & +9 \\
& Indoor sun protection (ventilated) & +9 \\
& Absorption greater than 50\% & +18 \\
"Winter" & Indoor sun protection (not ventilated) & +18 \\
& Underlying thermal insulation (panel) & +35 \\
& Unheated building & -12 \\
\hline
\end{tabular}

Table 4 Production conditions for the load conditions summer and winter in accordance with DIN 18008-1 (2010)

\begin{tabular}{lcc}
\hline Combination of actions & Atmospheric pressure $(\mathrm{hPa})$ & Temperature $\left({ }^{\circ} \mathrm{C}\right)$ \\
\hline "Summer" & 1030 & +19 \\
"Winter" & 990 & +27 \\
\hline
\end{tabular}

Glass thickness $\geq 4 \mathrm{~mm}$, installation height above ground $\leq 20 \mathrm{~m}$, heat absorption of the IGU $\leq 30 \%$, cavity-width $\leq 16 \mathrm{~mm}$, wind load $\leq 0.8 \mathrm{kN} / \mathrm{m}^{2}$, maximum difference of glass thicknesses $\leq 4 \mathrm{~mm}$.

This limitation is justified by an expectation of lower consequential damages in smaller glass surface areas. The exemption can be applied to most thermally insulating glass units installed in a majority of residential apartments and houses. In the case of sun-screening glass, however, absorption of more than $30 \%$ is possible, preventing the exemption of such glazing in the applications described.

The loads to be assumed in accordance with DIN 18008-1 (2010) for the calculation of climate load are listed in Tables 2, 3. The input values for production are shown in Table 4.

Figure 3 is meant to provide an overview of the design stresses of insulating glass units for which no increases are required per Table 3. The stresses are plotted as a function of the edge length for the edge length ratios $b / a=1$ and $b / a=4$. The stresses were calculated for symmetric triple IGU with a $16 \mathrm{~mm}$ cavity and both a $4 \mathrm{~mm}$ (black lines) and a $6 \mathrm{~mm}$ (red lines) glass thickness representing the IGU setups 4/16/4/16/4 and $6 / 16 / 4 / 16 / 6$. The combination of actions "summer" was assumed as the load condition. The stresses are only $+3.0 \%$ higher in absolute terms for the load condi- tion "winter". This small difference results from the deviating loads for altitude, meteorological fluctuation and temperature versus the load condition "summer" in combination with the respectively applicable partial safety factors. The calculation was carried out using an FE model with an immovable support as introduced in Sect. 2.1 and a rotational stiffness of $\mathrm{c}_{\varphi}=0$. In addition the design resistance $R_{\mathrm{d}}$ for float glass and heat strengthened glass are given for orientation.

If the conditions of the design exception for glass surface areas of less than $1.6 \mathrm{~m}^{2}$ according to DIN 18008-2 (2010) as described earlier are not fulfilled, heat strengthened or toughened glass has to be used above a maximum principal stress of $18 \mathrm{MPa}$. In this case, the assumption of a flexible edge seal could lead to a more economic design starting from an edge length ratio of $b / a=1$. If the exception conditions are fulfilled, the following discussion has to be considered.

For IGU with edge length ratios of $b / a=1$ (dashed lines), for every edge length float glass can be inserted according to DIN 18008-2 (2010) . That's because the glass surface area of $1.6 \mathrm{~m}^{2}$ is exceeded only starting at $1.27 \mathrm{~m}$ short edge length $\left(1.27 \mathrm{~m} \times 1.27 \mathrm{~m}=1.61 \mathrm{~m}^{2}\right)$, yet the maximum principal stress falls behind the resistance stress of float glass of $18 \mathrm{MPa}$ only starting at $0.9 \mathrm{~m} \mathrm{(4} \mathrm{mm} \mathrm{glass} \mathrm{thickness,} \mathrm{black} \mathrm{line} \mathrm{for} b / a=1$ )

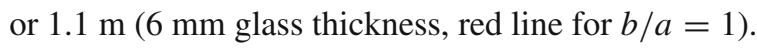


Fig. 3 Design stresses of the glass panes in load condition "summer" in accordance with DIN 18008-1 (2010) for symmetric triple IGU in vertical application with the setups 4/16/4/16/4 (4 mm glass thickness) and 6/16/4/16/6 (6 mm glass thickness) with calculation per DIN 18008-2 (2010) (with $a$ length short edges and $b$ length long edges)
Triple IGU with $16 \mathrm{~mm}$ cavity in load condition "summer"

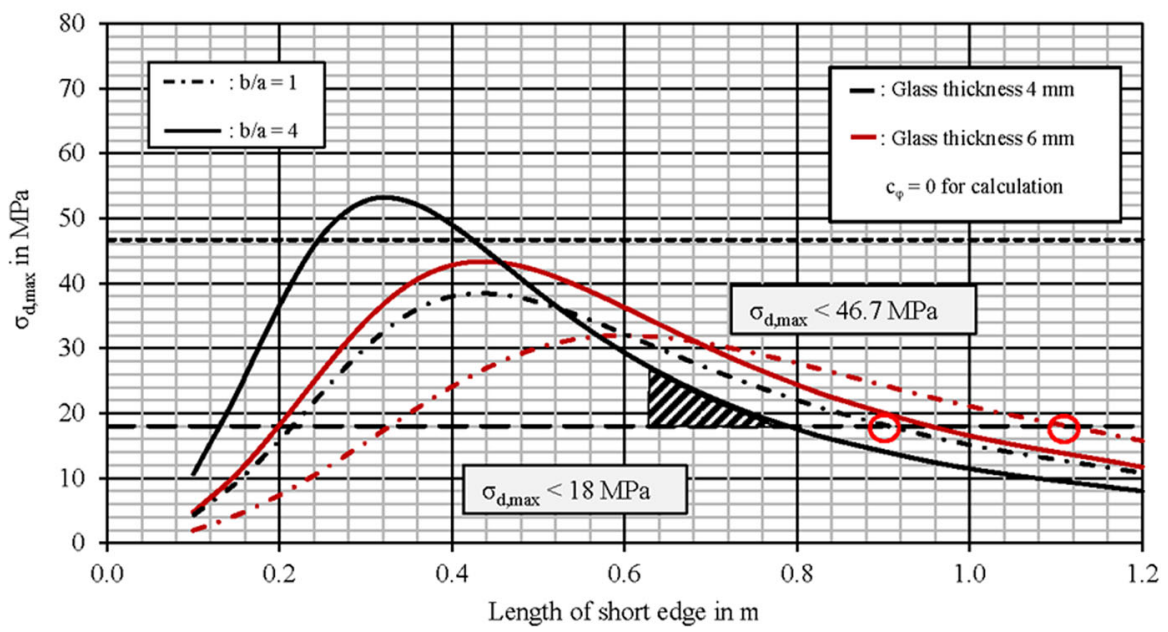

These intersections are marked with a red circle in Fig. 3.

For an edge length ratio of $b / a=4$, the glass surface area exceeds $1.6 \mathrm{~m}^{2}$ above an edge length of $a=0.63 \mathrm{~m}\left(0.63 \mathrm{~m} \times 0.63 \mathrm{~m}=1.6 \mathrm{~m}^{2}\right)$. The maximum principal stress is falling behind $18 \mathrm{MPa}$ above an edge length of $0.8 \mathrm{~m}$ for symmetric IGU with $4 \mathrm{~mm}$ glass thickness and above a short edge length of $0.94 \mathrm{~m}$ for symmetric IGU with $6 \mathrm{~mm}$ glass thickness, respectively. This means, that heat strengthened or toughened glass has to be used between edge lengths of 0.63 and $0.8 \mathrm{~m}$ for symmetric IGU with $4 \mathrm{~mm}$ glass thickness and between edge lengths of $0.63 \mathrm{~m}$ and $0.94 \mathrm{~m}$ for symmetric IGU with $6 \mathrm{~mm}$ glass thickness according to DIN 18008-2 (2010) and DIN 18008-1 (2010). The area is illustrated exemplarily in a white, cross-hatched pattern for the edge length ratio $b / a=4$ and a glass thickness of $4 \mathrm{~mm}$ in Fig. 3. This effect is starting to get relevant above an edge length ratio of $b / a=2.7$ according to own calculations.

For these areas, economic advantages for the design could become tangible by assumption of a flexible edge seal if the other exception conditions in accordance with DIN 18008-2 (2010) are fulfilled except the glass area of less than $1.6 \mathrm{~m}^{2}$.

\section{Experimental results and discussion}

\subsection{Comparison of calculated and experimentally determined climate loads}

In order to be able to evaluate the mechanical behaviour of the edge seal under climate load and compare "actual" arising climate load with computational climate load, specimens of insulating glass units were subjected to a climate test procedure based on EN 1279-2 (2003) with 56 cycles at -18 to $+53{ }^{\circ} \mathrm{C}$, in which each cycle took $12 \mathrm{~h}$ (cf. Fig. 4a). The further 7-week storage at $+58^{\circ} \mathrm{C}$ was also carried out; it is not, however, a part of this article. The specimens were equipped with wireless pressure and temperature sensors in one cavity as well as with displacement transducers at least at the mid-point of a short edge to record the orthogonal deformation of the specimens between the outer glass panes during the test (cf. Fig. 4b). There were also strain gauges applied in the middle of one glass pane and on the edges, but due to temperature influences, the measured pressure was the most accurate value. Thus, it was not reasonable to use the values of the strain gauges to determine the stiffness of the edge seal. In Table 5 an overview of the tested specimens is shown. As secondary seal, polyurethane with a nominal covering of $3 \mathrm{~mm}$ was used.

By means of measurement of the atmospheric pressure and of the pressure in the cavity during the test, the resulting pressure difference and thereby the climate load on the specimens during the testing can be determined. To carry out a comparison between a conventional analytical determination of climate loads and actual arising climate loads, in Figs. 5, 6 the percentage differences are shown between analytically determined climate load taking into account the plate theory according to Kirchhoff and the experimentally determined climate loads. Illustrated here are the results of three specimens whose qualitative courses reflect the 

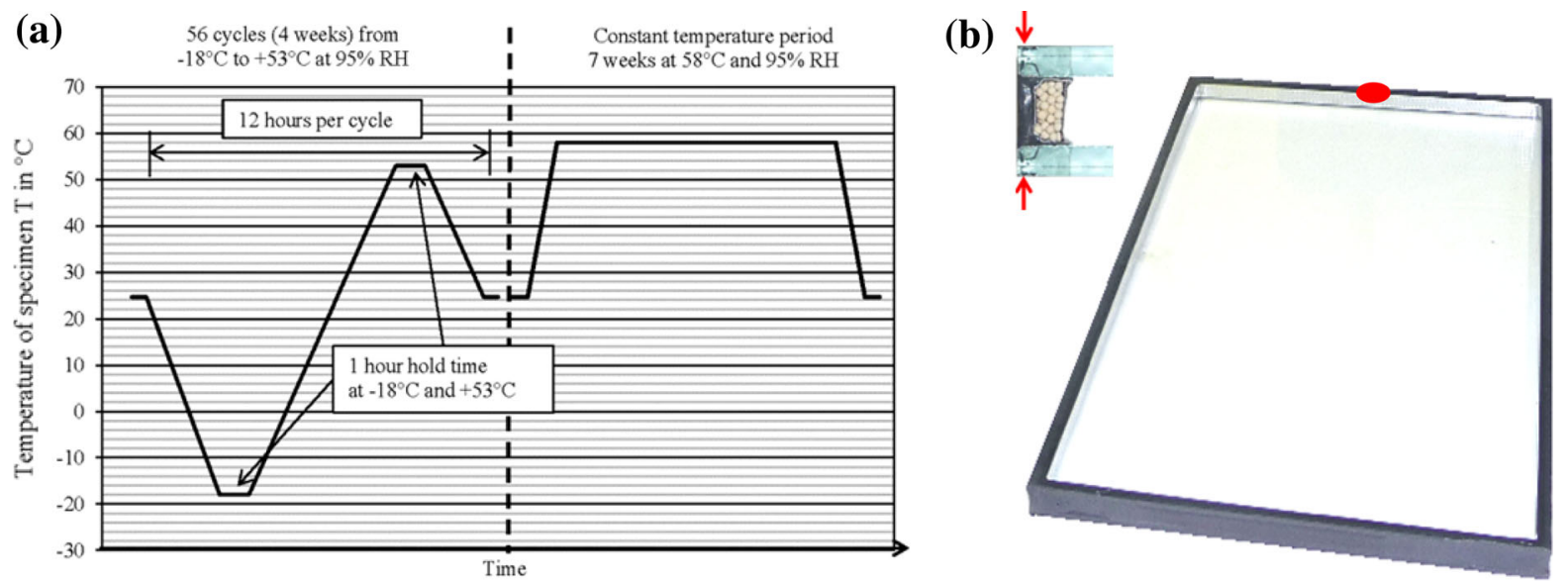

Fig. 4 a Climate test in accordance with EN 1279-2 (2003) and b measurement point of the displacement transducer

Table 5 Overview of dimensions and setups of the tested specimens

\begin{tabular}{lll}
\hline Dimensions & $\begin{array}{l}\text { Specimen setup } t_{\mathrm{g}} / w_{\mathrm{c}} / t_{\mathrm{g}} \text { (double IGU) } \\
\text { and } t_{\mathrm{g}} / w_{\mathrm{c}} / t_{\mathrm{g}} / w_{\mathrm{c}} / t_{\mathrm{g}}(\text { triple IGU) }\end{array}$ & Number \\
\hline $350 \mathrm{~mm} \times 500 \mathrm{~mm}$ & $4 / 12 / 4$ & $2+3(2$ tests $)$ \\
& $4 / 12 / 4 / 12 / 4$ & 2 \\
& $3 / 12 / 3$ & 2 \\
& $3 / 12 / 3 / 12 / 3$ & 2 \\
$12 / 12 / 12$ & 2 \\
& $12 / 12 / 4 / 12 / 12$ & 2 \\
& $4 / 18 / 4$ & 2 \\
& $4 / 18 / 4 / 18 / 4$ & 2 \\
$250 \mathrm{~mm} \times 1000 \mathrm{~mm}$ & $4 / 18 / 4 / 18 / 4$ & 3 \\
$650 \mathrm{~mm} \times 1000 \mathrm{~mm}$ & $4 / 12 / 4$ & 3 \\
\hline
\end{tabular}

with $t_{\mathrm{g}}=$ glass thickness

and $w_{\mathrm{c}}=$ cavity width

mens with relatively thin glass panes of only $3 \mathrm{~mm}$,

behaviour of all tested specimens in a representative fashion.

Shown are the percentage differences between the analytically and experimentally determined climate loads for values during the respective one-hour hold time at +53 and $-18^{\circ} \mathrm{C}$ for the climate cycling. The calculation of the analytical climate loads was carried out with the initial data which were measured at production (temperature and air pressure) as well as on the basis of the geometric measurements of the respective specimens. Here, positive values mean higher actual climate loads than those analytically calculated; negative values mean lower actual climate loads than those analytically calculated.

In order to interpret the results shown in Figs. 5, 6, the observations from Sect. 2.1 on disregarding the membrane action in the analytical calculation must be factored in. With that it is clear why for speci- higher experimentally determined climate loads result. Owing to the membrane action, it must be expected that values will be approximately $3 \%$ higher. Furthermore, inaccuracies arise in the analytical calculation of the climate loads, which result from the scatter of the input parameters. In addition to the air pressure and the temperature at production, this affects the assumed gas volume and/or the geometry of the specimens. The resulting deviation on the basis of the scatter of the input values amounts to approx. $\pm 2.5 \%$.

However, for triple IGU with thicker glass panes of 4 and $12 \mathrm{~mm}$, significantly lower climate loads arise in the first load cycle at +53 and $-18^{\circ} \mathrm{C}$, respectively. Lower experimental climate loads related to analytically calculated climate loads assumedly result from the deformation of the edge seal. 
Fig. 5 Symmetric IGU with $12 \mathrm{~mm}$ cavity and dimensions of $350 \mathrm{~mm} \times 500 \mathrm{~mm}$ during cycling with difference in calculated and experimentally determined climate loads at $+53{ }^{\circ} \mathrm{C}$ in percentage
Fig. 6 Symmetric IGU with $12 \mathrm{~mm}$ cavity and dimensions of $350 \mathrm{~mm} \times 500 \mathrm{~mm}$ during cycling with difference in calculated and experimental determined climate loads at $-18{ }^{\circ} \mathrm{C}$ in percentage. (Asterisk) After 28 cycles, the test was interrupted. Note that for specimens with $3 \mathrm{~mm}$ glass panes the climate load is relatively low with about $20 \mathrm{hPa}$ so small absolute changes cause greater changes in percentage

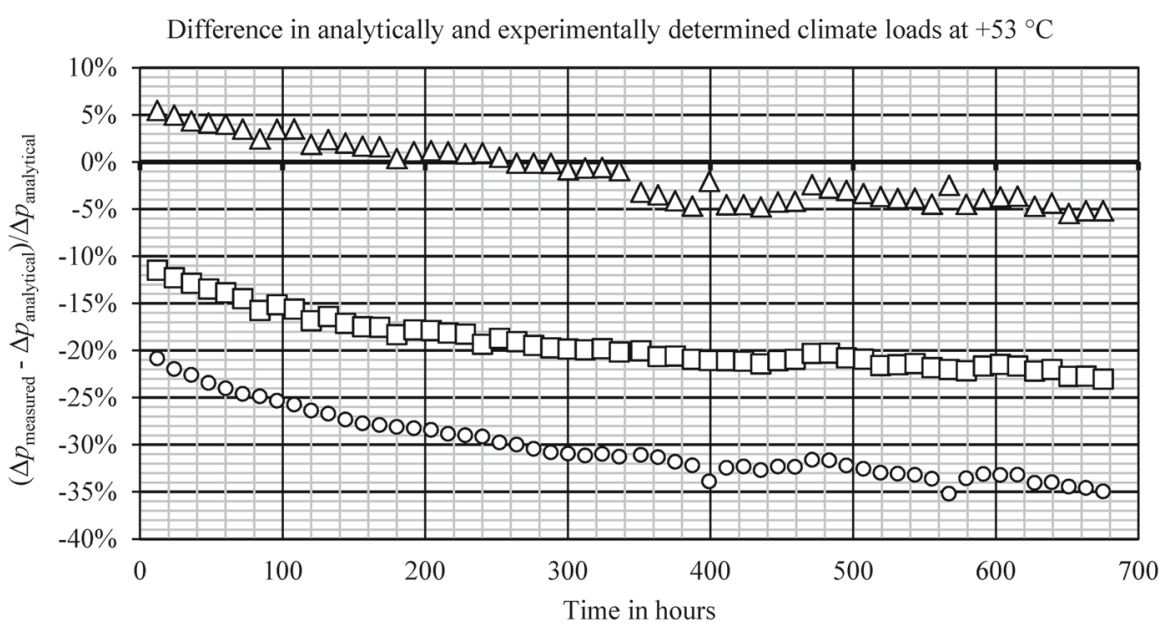

$\square 4 / 12 / 4 / 12 / 4$

$\Delta 3 / 12 / 3 / 12 / 3$

$012 / 12 / 4 / 12 / 12$

Difference in analytically and experimentally determined climate loads at $-18{ }^{\circ} \mathrm{C}$

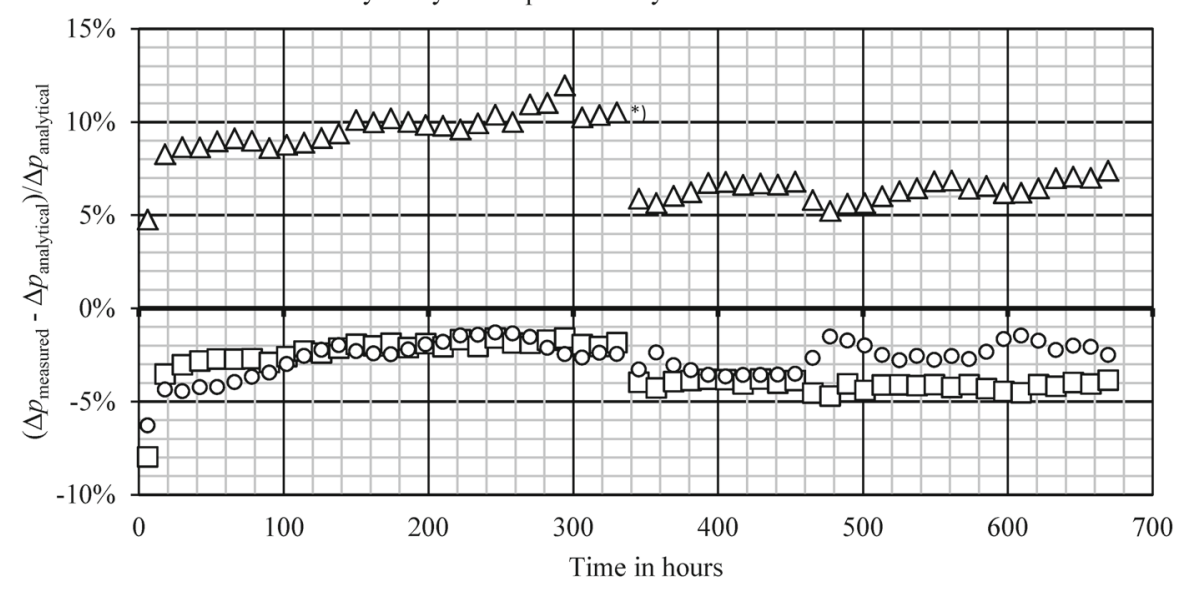

$\square 4 / 12 / 4 / 12 / 4$

$\Delta 3 / 12 / 3 / 12 / 3$

$012 / 12 / 4 / 12 / 12$

differences in Fig. 5 and 6 on the margin at the midpoint of a short edge. The accuracy of the displacement transducer is $\pm 60 \mu \mathrm{m}$. In addition to the deformations, the course of the air pressure during the test is shown, as this causes fluctuations in the climate loads and therefore also in the measured deformation.

The courses of the deformations of the edge seal lead to the conclusion that the differences between analytically calculated and experimentally determined climate load are significantly attributable to the deformation of the edge seal. At $+53{ }^{\circ} \mathrm{C}$ in the climate chamber, the deformations grow increasingly larger with increasing numbers of cycles, which corresponds with the rising climate load differences (that is, falling actual climate loads). Conversely, the course of the deformations of the edge seal at $-18^{\circ} \mathrm{C}$ corresponds well with 
Fig. 7 Deformation between the outer glass panes at the mid-point of one short edge of specimens with dimensions of $350 \mathrm{~mm} \times 500 \mathrm{~mm}$ with $12 \mathrm{~mm}$ cavity during cycling at $+53^{\circ} \mathrm{C}$

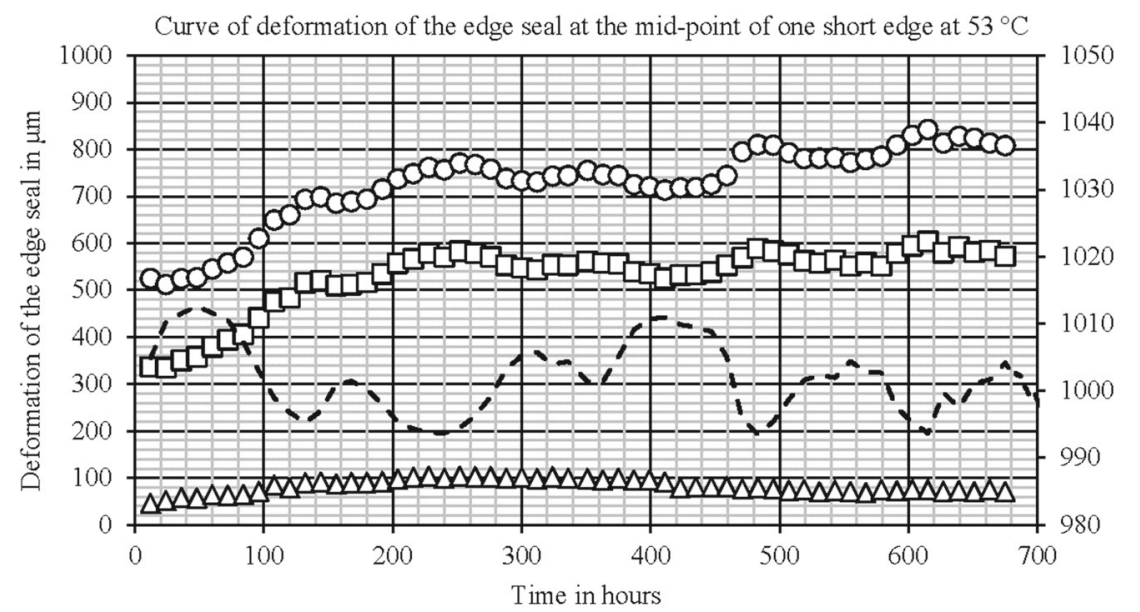

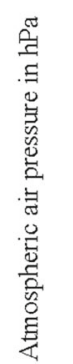

Fig. 8 Deformation between the outer glass panes at the mid-point of the short edges of specimens with dimensions of $350 \mathrm{~mm} \times 500 \mathrm{~mm}$ with $12 \mathrm{~mm}$ cavity during cycling at $-18^{\circ} \mathrm{C}$. (Asterisk) The values of the triple IGU with $4 \mathrm{~mm}$ glass panes had to be corrected ongoing from the 39th cycle due to measurement difficulties. While the quantitative value is not exact anymore, the qualitative trend is still valid)

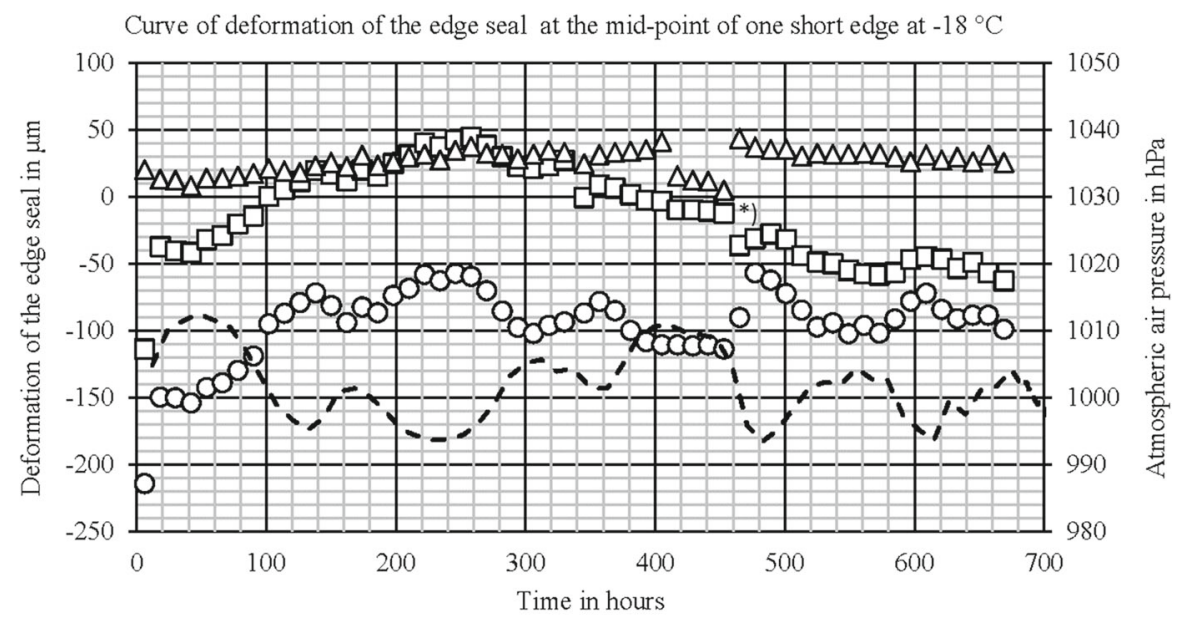

\begin{tabular}{llllll}
\hline & $4 / 12 / 4 / 12 / 4$ & 0 & $12 / 12 / 4 / 12 / 12$ & $\Delta$ & $3 / 12 / 3 / 12 / 3$
\end{tabular}$\quad$ - - Atmospheric air pressure the course of the climate load differences at $-18^{\circ} \mathrm{C}$, although the course of the deformations is strongly overlaid by the influence of the atmospheric air pressure.

After the first load cycle at $-18^{\circ} \mathrm{C}$ (cf. Fig. 8), there is a strong decrease of compression of the edge seal, by which the actual climate loads (cf. Fig. 6) also rise significantly. As described in the following section and schematically illustrated in Fig. 9, this-assumedlyresults from the load on the primary seal during the first cycle at higher temperatures:

Owing to the high positive pressure in the cavity, the polyisobutylene, that is, the primary seal, is assumedly not only stretched orthogonally toward the glass panes but also simultaneously pressed toward the outside against the secondary seal (cf. Fig. 9, Step 3). At room temperature the material possesses plastic ductility. The flow capacity and/or ductility increases with rising temperatures. At lower temperatures, however, the material becomes stiffer, making it more difficult to shape. For this reason, the first seal will assumedly no longer possess its original geometry once the temperature of $-18^{\circ} \mathrm{C}$ is reached for the second time, but rather feature a greater thickness (cf. Fig. 9, Step 5). This is an explanation of the lower compressions of the edge seal after the first cycle. 
With the help of the measured deformations of the edge seal and of the experimentally determined pressure differences in the cavity of the specimens, spring stiffnesses in tension for the edge seal at $+53{ }^{\circ} \mathrm{C}$ can be calculated using the FE model. This is explained in more detail in the following section, and the influence on the design is discussed.

\subsection{Influence of a flexible edge seal on the verification of the glass in ultimate limit state}

For the edge seal, an effective spring stiffness in tension calculation was made on the basis of the data from the tests for a covering of $3 \mathrm{~mm}$ polyurethane for the first load cycle at $+53{ }^{\circ} \mathrm{C}$ of $3 \mathrm{~N} / \mathrm{mm}$ to $4 \mathrm{~N} / \mathrm{mm}$ per millimetre edge length. For the 28th cycle, the effective spring stiffness in tension is still approximately $1.5-2 \mathrm{~N} / \mathrm{mm}$ per millimetre edge length. The calculation of the effective spring stiffness in tension was done by calibrating the spring stiffness assumed in an FE model until the experimentally determined climate load and deformations of the edge seal accorded with the calculated values for the specimens listed in Table 5 (cf. Buddenberg et al. 2015). Since the pressure in triple IGU was only measured in one cavity, it cannot be experimentally verified that the pressure is equal in both cavities. But in the range of production and measurement accuracies the pressure of both cavities can approximately be supposed as equal.

It is noted that these stiffnesses can only be assumed for loads which interact at low velocities, as the resistance of the primary seal made of polyisobutylene is strongly dependent on time; also, the elastomeric material for the second seal exhibits pronounced creep behaviour.

While the calculated effective spring stiffness in tension of the edge seal is factored in, the rotational stiffness $c_{\varphi}$ is not. It could not be determined exactly within this project, but it should lie below $200 \mathrm{Nmm} / \mathrm{rad}$ per millimetre edge length, which follows from calculations on the basis of the data obtained on deformation of the edge seal and of the determined pressure differences. Other authors determined a rotational spring stiffness of about $100 \mathrm{Nmm} / \mathrm{rad}$ per millimetre edge length for edge seals with a covering of $4 \mathrm{~mm}$ polysulphide at relatively high deformation velocities at room temperature (Ensslen et al. 2014). Assumedly the rotational stiffness is hardly above zero considering the test conditions within this project with low deformation velocity and higher temperature. However, the influence of the rotational stiffness of maximally $200 \mathrm{Nmm} / \mathrm{rad}$ per millimetre edge length on the maximum glass stresses would be low with $\pm 3.0 \%$ for the investigated setups and dimensions.

In Figs. 10, 11 and 12, three curves of maximum principal stress in the glass panes versus small edge length are provided respectively. One curve (grey) represents the results for an immovable edge support according to Fig. 3. The other curves represent the values under consideration of a flexible edge seal in tension and compression without a rotational stiffness (black: $4 \mathrm{~N} / \mathrm{mm}^{2}$, red: $2 \mathrm{~N} / \mathrm{mm}^{2}$ ). Thus the influence on stress considering a flexible edge seal in contrast to an immovable edge seal can be compared directly. The calculations were done using the FE model described in Sect. 2.1 but with spring elements Combin14 at the edges in addition.

Figure 10 shows the resulting stresses for symmetric IGU with $4 \mathrm{~mm}$ thick glass panes based on the load conditions "summer" according to Table 2. Figures 11 and 12 illustrate the results based on the load conditions "summer" making allowance for an heat absorption of more than $50 \%$, which can be present in sunscreening glass. This means that the temperature has to be increased by $+18 \mathrm{~K}$ according to Table 3 . In Fig. 11 the stresses are shown for symmetric IGU with $4 \mathrm{~mm}$ thick glass and, as a thicker glass can be chosen for the design in addition to another glass type, the effects of the choice of a $6 \mathrm{~mm}$ thick glass are illustrated in Fig. 12.

The assumption of a flexible edge seal in the calculation of glass stresses for the load condition "summer" results in lower stresses. In the load condition "winter" on the basis of the performed tests (cf. Sect. 3.1) no flexibility of the edge seal can be assumed. Hence the load conditions "winter" will be decisive. Thus no advantages result for the design of the standard load condition in the calculation of the climate load.

At a heat absorption of more than $50 \%$, the assumption of a flexible edge seal with an effective spring stiffness of $2 \mathrm{~N} / \mathrm{mm}^{2}$ in the calculation of the glass stresses results in maximum differences of $20 \%$ in $4 \mathrm{~mm}$ thick glass and $25 \%$ in $6 \mathrm{~mm}$ thick glass for an edge length ratio of $b / a=4$ (cf. Figs. 11, 12 grey and red lines). Under consideration of the required temperature increases of $+18 \mathrm{~K}$ owing to a higher heat absorption, the load condition "summer" versus "winter" is, in addition, decisive. Moreover, the verification 


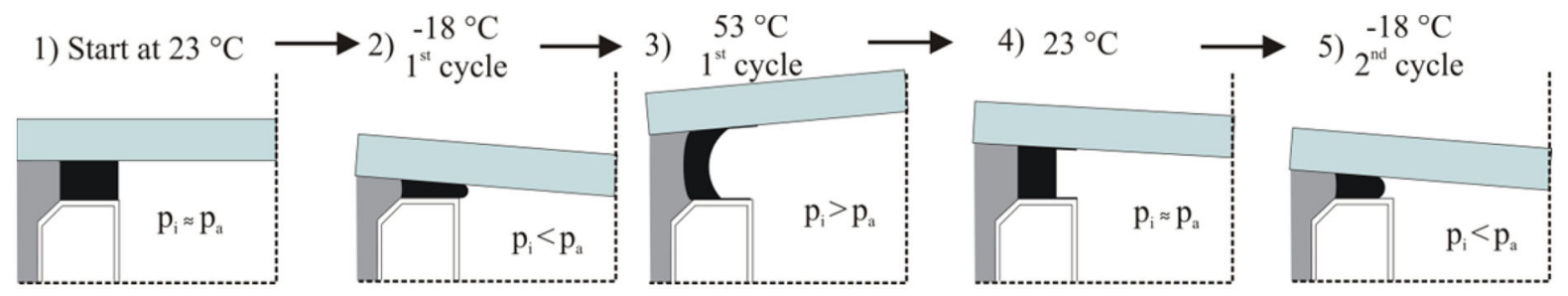

Fig. 9 Assumed deformation of the primary seal in the first and second cycle during climate testing according to EN 1279-2 (2003)

Fig. 10 Design stresses of the glass panes for symmetric IGU in vertical application in load condition "summer" with $4 \mathrm{~mm}$ glass thickness (with $a$ length short edge and $b$ length long edge)
Fig. 11 Design stresses of the glass panes for symmetric IGU in vertical application in load condition "summer" and a thermal absorption $>50 \%$ with $4 \mathrm{~mm}$ glass thickness (with $a$ length short edge and $b$ length long edge)
Triple IGU with $16 \mathrm{~mm}$ cavity and $4 \mathrm{~mm}$ glass in load condition "summer"

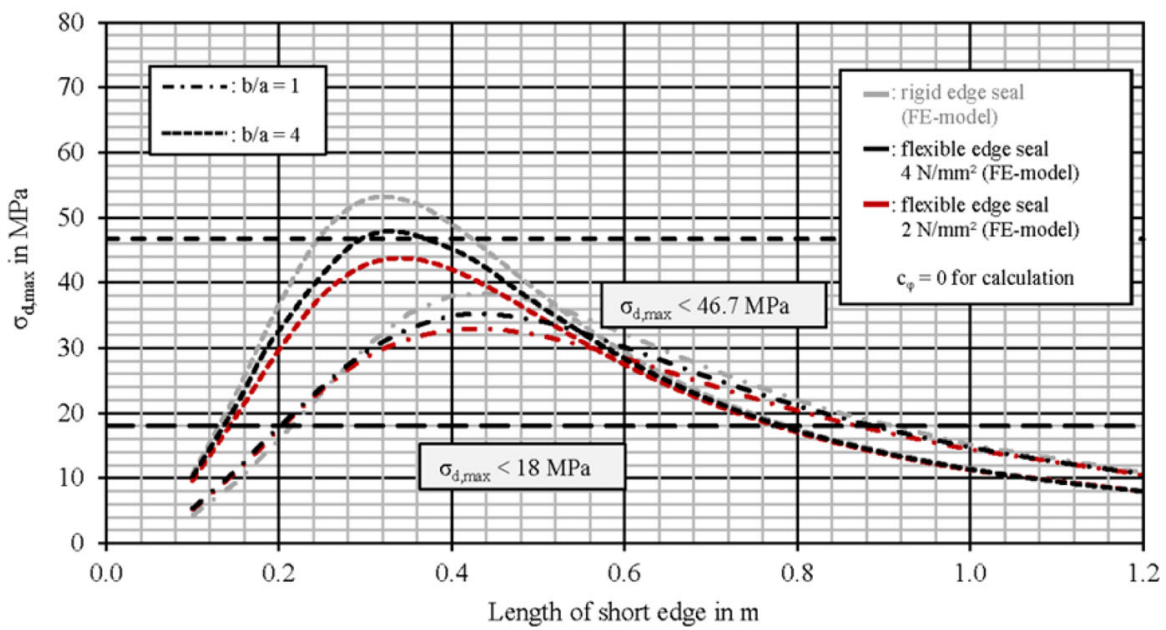

Triple IGU with $16 \mathrm{~mm}$ cavity and $4 \mathrm{~mm}$ glass in load condition "summer" and an absorption $>50 \%$

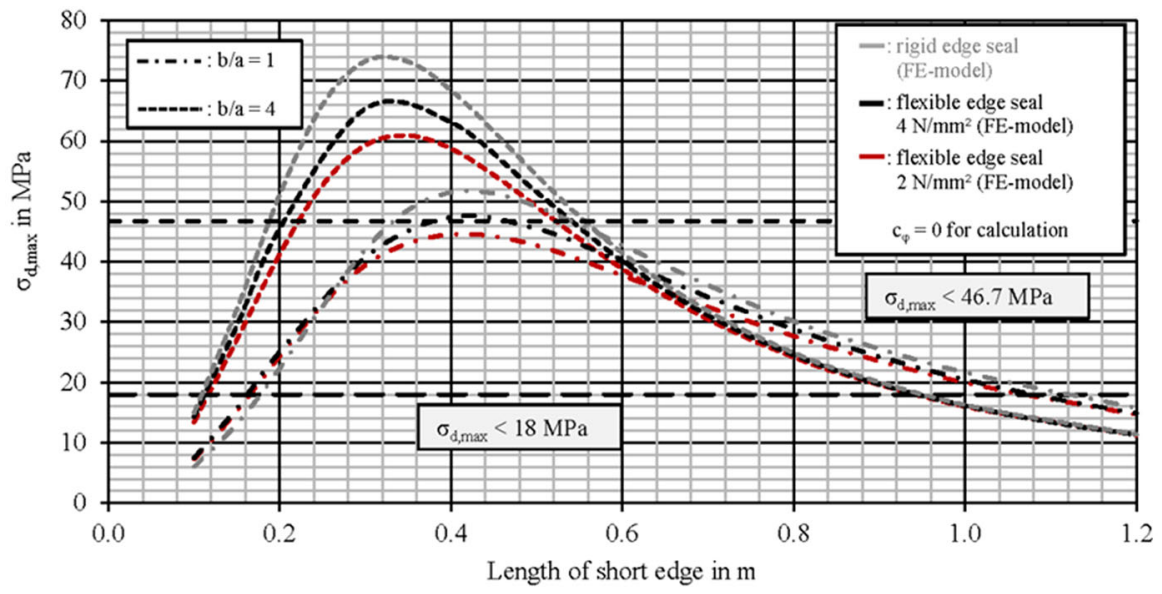

of load bearing capacity, also for insulating glass units under $1.6 \mathrm{~m}^{2}$ glass surface area, must be provided, as the conditions of the exemption from the regulation are no longer fulfilled. Economic advantages already result in a small area of the edge lengths above $1.0 \mathrm{~m}$ for an edge length ratio of $b / a=1$. Here, the use of float glass instead of heat strengthened or toughened glass is possible. If, owing to design constraints, thicker glass panes are necessary, this area will shift in the direction of greater edge lengths.

Because of a better post-fracture performance, laminated glass of heat strengthened instead of monolithic glass panes or laminated glass of toughened glass must be used for horizontal overhead glazing per 
Fig. 12 Design stresses of the glass panes for symmetric IGU in vertical application in load condition "summer" and a thermal absorption $>50 \%$ with $6 \mathrm{~mm}$ glass thickness (with $a$ length short edges and $b$ length long edge)
Triple IGU with $16 \mathrm{~mm}$ cavity and $6 \mathrm{~mm}$ glass in load condition "summer" and an absorption $>50 \%$

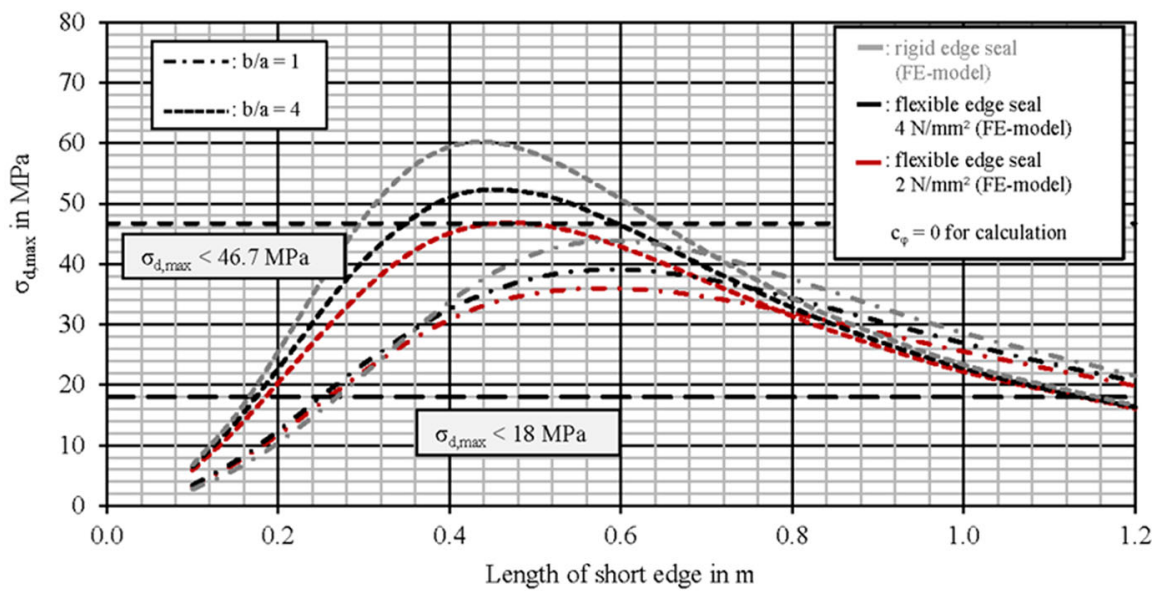

DIN 18008-2 (2010), as heat strengthened fractures coarsely and the fragments remain bonded to the interlayer film. Without assumption of a flexible edge seal, only toughened glass could be used in the range of shorter edge lengths between 0.32 and $0.55 \mathrm{~m}$, however, so that the edge lengths or glass thickness would have to be increased. Taking the flexibility of the edge seal into account, the advantage of being able to use heat strengthened in consistent edge lengths would then come into play. But note that the results shown in Fig. 12 are only valid for full force transmission of the interlayer. For horizontal glazing however, another combination of actions, e.g. with snow, can also become decisive. This must be checked case by case.

To be able to assume flexibility of the edge seal, it must also be able to expand freely in pragmatic applications. However, the free expansion of the edge seal under climate load is not readily possible, as insulating glass units are usually clamped in a frame-unless they are used in a structural sealant glazing (SSG) application. A closer inspection would entail examination of the resistance of the clamping. The numerous systems in this area make such examinations difficult, however, as at the time of the design of the glass panes it is not yet known which construction will be used in the facade being planned. But note that a free expansion of the edge seal can reduce the durability of an insulating glass unit. This means that the ingress of water vapour is increased over the service life of the unit and a fogging of the IGU in the cavity is more likely (Buddenberg et al. 2015).

\section{Summary}

The comparison of experimentally determined climate loads and analytically calculated climate loads in cyclic temperature loading of -18 and $+53{ }^{\circ} \mathrm{C}$ shows that the actual climate loads at $+53^{\circ} \mathrm{C}$ are lower than calculated. With increasing numbers of load cycles the actual climate load decreases further. At $-18^{\circ} \mathrm{C}$ the calculated and actual climate loads are hardly distinguishable. The lower climate loads at $+53^{\circ} \mathrm{C}$ are attributable to the deformation of the edge seal during the measured cyclic temperature loading. In this process it is observed that the edge seal is more flexible with a rising number of load cycles until a constant level has been reached. At $-18^{\circ} \mathrm{C}$ in contrast, there is only a low level of compression and there are no permanent changes in rigidity after the first load cycle.

For an examination to determine the extent to which the assumption of a flexible edge seal in the ultimate limit state of the glass panes exercises influence on the design, glass stresses for various load conditions, dimensions and setups with and without a movable edge seal were calculated. This affects triple IGU with a $16 \mathrm{~mm}$ cavity and 4 and $6 \mathrm{~mm}$ thick glass panes in load condition "summer", and in load condition "summer" with a heat absorption level of the IGU at greater than $50 \%$, as can be present in sun-screening glass.

With the assumption of a flexible edge seal in the calculation, lower glass stresses result than under assumption of an immovable edge seal. Because however in the load condition "winter" on the basis of the experimen- 
tally determined data no significant deformation of the edge seal can be assumed, this becomes decisive versus the load condition "summer". If however for the load condition "summer" it is necessary to assume a temperature increase-e.g. owing to a heat absorption level of the glass panes of more than $30 \%$-the load condition can become decisive.

For IGU deviating from rectangular, planar shapes and symmetric setups, the influence of a flexible edge seal on glass stresses caused by climate loads must be examined separately (e.g. for curved, round or triangular insulating glass units). Further, the determination of effective spring stiffness in tension for the edge seal in materials other than the examined polyurethane and coverings higher than $3 \mathrm{~mm}$ is advisable.

Acknowledgments This work has been conducted with the Deutscher Ausschuss für Stahlbau e. V. (DASt) and has been funded by the Arbeitsgemeinschaft industrieller Forschungsvereinigungen $(\mathrm{AiF})$ in the framework of the programme to promote industrial research and development (IGF project $17235 \mathrm{~N}-$ DuraSeal) by the Federal Ministry of Economics and Technology based on a decision of the German parliament (Deutscher Bundestag).

\section{References}

Buddenberg, S., Hof, P., Oechsner, M.: DuraSeal—durability of insulating glass units: influence of climate ageing \& climate loads according to DIN EN 1279. In: Glass Performance Days 2015-Conference Proceedings, Glaston Oy, Tampere (2015)
DIN 18008-1: Glas im Bauwesen-Bemessungs- und Konstruktionsregeln-Teil 1: Begriffe und allgemeine Grundlagen (2010)

DIN 18008-2: Glas im Bauwesen-Bemessungs- und Konstruktionsregeln-Teil 2: Linienförmig gelagerte Verglasungen (2010)

EN 12150-1: Thermally toughened soda lime silicate safety glass. Part 1: Definition and description (2015)

EN 1279-2: Glass in building-Insulating glass units. Part 2: Long term test method and requirements for moisture penetration (2003)

EN 1863-1: Heat strengthened soda lime silicate glass. Part 1: Definition and description (2012)

EN 1990: Basis of structural design (2010)

EN 572-1: Glass in building-Basic soda lime silicate glass products. Part 1: Definitions and general physical and mechanical properties (2012)

Ensslen, F., Becker, H.: Wittwer W: Modell für den nachgiebigen Randverbund von Mehrscheiben-Isoliergläsern. In: Weller, B., Tasche, S. (eds.) Glasbau 2014. Wilhelm Ernst \& Sohn, Dresden (2014)

Feldmeier, F.: Belastung des tragenden Randverbundes von Isolierglas bei Structural Glazing durch klimatische Einflüsse. Fraunhofer IRB Verlag, Stuttgart (1999) 